\title{
Article
}

\section{The Effect of the Substrate on the Optic Performance of Retro-Reflective Coatings: An In-Lab Investigation}

\author{
Alessia Di Giuseppe ${ }^{1}\left(\mathbb{D}\right.$, Marta Cardinali ${ }^{1, *(\mathbb{D})}$, Beatrice Castellani ${ }^{1,2}\left(\mathbb{D}\right.$, Mirko Filipponi $^{1,2}(\mathbb{D}$, \\ Alberto Maria Gambelli ${ }^{2}\left(\mathbb{D}\right.$, Lucio Postrioti ${ }^{2}$, Andrea Nicolini ${ }^{1,2}\left(\mathbb{D}\right.$ and Federico Rossi ${ }^{1,2} \mathbb{}$ \\ 1 CIRIAF, Interuniversity Research Centre on Pollution and Environment "M. Felli", Via G. Duranti 67, \\ 06125 Perugia, Italy; alessia.digiuseppe@crbnet.it (A.D.G.); beatrice.castellani@unipg.it (B.C.); \\ mirko.filipponi@unipg.it (M.F.); andrea.nicolini@unipg.it (A.N.); federico.rossi@unipg.it (F.R.) \\ 2 Department of Engineering, University of Perugia, Via G. Duranti 93, 06125 Perugia, Italy; \\ alberto.mariagambelli@gmail.com (A.M.G.); lucio.postrioti@unipg.it (L.P.) \\ * Correspondence: cardinali@crbnet.it
}

check for updates

Citation: Di Giuseppe, A.; Cardinali, M.; Castellani, B.; Filipponi, M.; Gambelli, A.M.; Postrioti, L.; Nicolini, A.; Rossi, F. The Effect of the Substrate on the Optic Performance of Retro-Reflective Coatings: An In-Lab Investigation. Energies 2021, 14, 2921. https://doi.org/10.3390/en14102921

Academic Editor: Adrián

Mota Babiloni

Received: 19 April 2021

Accepted: 16 May 2021

Published: 18 May 2021

Publisher's Note: MDPI stays neutral with regard to jurisdictional claims in published maps and institutional affiliations.

Copyright: (c) 2021 by the authors. Licensee MDPI, Basel, Switzerland. This article is an open access article distributed under the terms and conditions of the Creative Commons Attribution (CC BY) license (https:// creativecommons.org/licenses/by/ $4.0 /)$.

\begin{abstract}
Retro-reflectivity is a promising surface capability, which has attracted the interest of researchers for building applications in order to counteract Urban Heat Island (UHI) effects. This work aims at studying the impact of the substrate material on the optic performance of retro-reflective (RR) coatings. Three types of substrate materials were investigated: smooth pine wood panels, rough plywood panels, and smooth acetate sheets. The RR coating samples were made by firstly adding a high reflective white paint onto the substrate material and a homogeneous RR glass beads layer on the top. As a reference case, also diffusive samples, without RR beads, were developed. Samples have been tested through a spectrophotometric and an angular reflectivity analysis. Results show that, despite a lower global reflectance of the RR samples with respect to the diffusive ones, the glass beads coating provides a good retro-reflective capability to all the diffusive samples. Additionally, the roughest RR sample exhibited the highest RR capability of up to $16 \%$, with respect to the other smoother samples. Future developments may involve the optimum design of RR coatings, in terms of their optic performance by varying the substrate materials and roughness, the glass beads density and dimension.
\end{abstract}

Keywords: Urban Heat Island; retro-reflective coatings; glass beads; optic analysis; angular reflectivity

\section{Introduction}

During the last decades, cities are continuously suffering from several anthropizationrelated issues: human activities, in fact, generate high levels of air pollution, anthropogenic heat, energy consumptions, and greenhouse gases emissions, which contribute to the so-called Urban Heat Island (UHI) effect [1,2]. Such a phenomenon occurs with an increase in urban air temperatures with respect to the natural, not populated areas nearby [3]. UHI could also be worsened by the ongoing climate change, which is responsible for increasingly extreme events occurrence, more frequent heatwaves, and urban overheating [4-6]. In Yenneti et al. (2020) [7], a collection of studies on UHI intensity in 10 different Australian cities is reported, showing that the UHI magnitude ranges between 1 and $13{ }^{\circ} \mathrm{C}$ in the investigated sites.

Urban pattern and building materials could also have a strong impact on UHI [8]: In dense city contexts, where urban canyon configurations are more frequent, incident solar radiation could get trapped inside the urban structure, because of consecutive reflections of solar radiation between facing buildings. Furthermore, the unstoppable urbanization results in an increase of built surfaces, usually made of artificial materials, at the expense of vegetation, natural ground, and greenery. The most commonly used materials for building envelopes and pavements are typically characterized by low solar reflectance and thermal emissivity, resulting in a higher amount of solar radiation being absorbed by urban surfaces. 
These facts lead to a further overheating, contributing also to the depletion of the urban environment and outdoor thermal comfort [7].

In this panorama, it becomes necessary to develop new solutions for building envelopes and urban surfaces, improving their optic and radiative features. Literature studies [9-11] on innovative coatings for UHI mitigation and building energy savings include high-reflective and infrared reflective materials, thermochromic and fluorescent coatings, daytime radiative coolers, and retro-reflective (RR) materials.

Among them, RR materials possess a unique feature that has caught the attention of researchers during the last years, especially regarding their possible application in building envelopes and urban surfaces [12,13]. Such materials, in fact, are able to reflect the sunlight predominantly toward the same direction of incidence [13]. Several studies have proved their effectiveness, particularly in Urban Canyons, where they could avoid the onset of multiple reflections between facing surfaces, leading to a cooling effect inside the canyon [14-17]. The RR capability is given by the peculiar surface microstructure, which may consist of reflective prisms (cube corner RR type), or glass beads arranged over a reflective layer (glass beads RR type) [18,19]. In Sakai and Iyota (2017) [20], two new typologies of RR materials were presented: the directional RR type and the rough-surface $\mathrm{RR}$ one. The latter is based on the contribution to retro-reflectivity given by the surface roughness. With regard to this aspect, a recent study developed a new BRDF model for prismatic RR materials, taking into account also the surface roughness [21].

This work aims to investigate the impact that the substrate material could have in terms of retro-reflective capability of a glass beads RR coating, applied on the top of the surface. To this aim, three kinds of substrate materials with different roughness have been tested: a smooth pine wood panel, a rough plywood panel, and a smooth acetate sheet. For each kind of substrate, a RR glass beads sample and a diffusive sample, without glass beads, have been made. The optic performance of the tested materials was determined through a spectrophotometric and an angular reflectivity analysis, in order to explore the potential impact of the substrate material and its roughness on the final RR capability.

\section{Motivation}

The present research represents a preliminary step for the development of the optimum design of RR coatings to be used for building application, as an alternative to the commercial existing RR materials, originally conceived for road and traffic signs. In fact, RR coatings could contribute to decrease the energy entrapped inside an urban canyon, due to their angular properties of reflection. The application of RR both on walls and pavements of the urban canyon could provide a better mitigation of UHI, avoiding multiple reflections between facing surfaces $[12-17,22]$.

Furthermore, RR materials could be used in combination with diffusive materials in photovoltaic fields, in order to increase the electric energy produced by the downward facing panel of a bifacial photovoltaic system. Consequently, this study may provide useful information about the most suitable substrate to be applied for RR coatings.

In order to define the optimal RR coatings, this study constitutes a first effort in the investigation of the optimal substrate to be used for RR glass beads coatings, in terms of the material's typology and roughness.

In particular, data concerning the optic performance in terms of global reflectance and directivity of three types of substrate material were collected and discussed in the following sections.

\section{Materials and Methods}

In this section, the three tested substrate materials are firstly described and then the applied methodology is presented, involving a spectrophotometric and an angular directivity analysis. 


\subsection{Description of Samples}

Three types of substrates with different materials and roughness were tested in order to study the impact of the substrate on the optic performance of RR coatings, made of a high-reflective white paint with glass beads embedded on it.

The three substrate materials are presented below:

- SW: smooth pine wood panel;

- RW: rough plywood panel;

- SA: smooth acetate sheet.

These materials are characterized by a different roughness, which has been measured with a Taylor Hobson Precision Surtronic 25 [23] portable instrument. For the SA sample, one measure has been carried out, as the surface is extremely smooth and homogeneous. For the two wood-based substrates, two measures have been performed, as their surfaces are not homogeneous. In particular, for the SW sample, a first measure was carried out in the same direction of wood fibers, whereas the second one was conducted perpendicular to them. For the RW sample, the roughness was measured in two different portions of the surface. Results are presented in Table 1, concerning the range of measured values of roughness indices $R_{a}$ and $R_{z}$ for each substrate sample.

Table 1. Roughness measurements for the three substrate samples.

\begin{tabular}{ccc}
\hline Substrate Sample & $\mathbf{R}_{\mathbf{a}}[\boldsymbol{\mu m}]$ & $\mathbf{R}_{\mathbf{z}}[\boldsymbol{\mu m}]$ \\
\hline SW & $1.70 \div 4.92$ & $9.80 \div 27.80$ \\
RW & $2.82 \div 6.00$ & $15.40 \div 36.00$ \\
SA & 0.08 & 0.50 \\
\hline
\end{tabular}

Results show that the material with the lowest roughness is the SA sample, followed by the SW sample. The highest roughness values are exhibited by the RW substrate, which has the most inhomogeneous surface appearance.

Starting from these three different substrates with increasing roughness, the same glass beads RR coating was applied to them, in order to investigate the impact of the substrate on their optic performance. The RR coating samples were made with a high reflective white paint supplied by INDEX Construction Systems and Products S.p.A., on which a homogeneous RR glass beads layer was settled on the top. RR glass beads were supplied by PROCHIMA s.r.l. with an average diameter $0.1-0.2 \mathrm{~mm}$.

The three RR coating samples are defined as follows:

- $\quad R_{S W}$ : glass beads RR coating applied on SW panel (Figure 1a);

- $\quad R_{R W}$ : glass beads RR coating applied on RW panel (Figure 1b);

- $\mathrm{RR}_{\mathrm{SA}}$ : glass beads RR coating applied on SA sheet (Figure 1c).

As a reference case, also a diffusive sample for each typology of substrate, without RR glass beads, was realized. The three diffusive samples were mentioned as DIFF

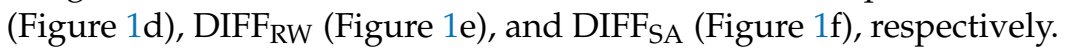

Figure 1 shows the investigated RR and diffusive samples. The size of the substrate materials was $20 \mathrm{~cm} \times 20 \mathrm{~cm}$ both for $R_{\mathrm{SW}} / \mathrm{DIFF}_{\mathrm{SW}}$ and for $\mathrm{RR}_{\mathrm{RW}} / \mathrm{DIFF}_{\mathrm{RW}}$ samples, while it was $21 \mathrm{~cm} \times 29.7 \mathrm{~cm}$ for the $R_{\mathrm{SA}} / \mathrm{DIFF}_{\mathrm{SA}}$ sample. 


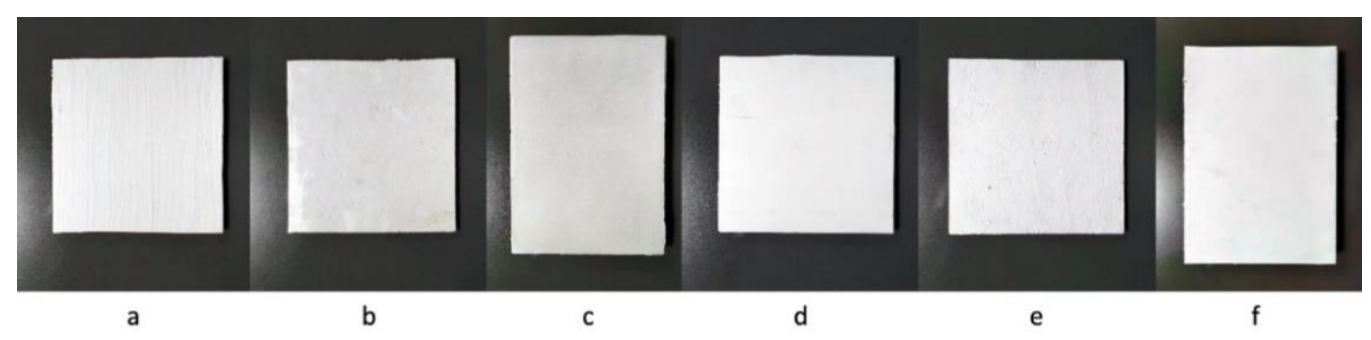

Figure 1. Investigated $R R$ and diffusive coating samples on different substrates: (a) $R_{S W}$; $(\mathbf{b}) R_{R W}$; (c) $\mathrm{RR}_{\mathrm{SA}} ;(\mathbf{d}) \mathrm{DIFF}_{\mathrm{SW}} ;(\mathbf{e}) \mathrm{DIFF}_{\mathrm{RW}} ;(\mathbf{f}) \mathrm{DIFF}_{\mathrm{SA}}$.

\subsection{Methodology}

For the investigation of the substrate optic performances, the following methodology was applied:

- Firstly, a spectrophotometric analysis was conducted, in order to assess the solar reflectance of samples using a spectrophotometer equipped with an integrating sphere which covers UV, VIS, and NIR regions. The range of measurements is $250-2500 \mathrm{~nm}$, which includes the $99 \%$ of solar energy;

- Finally, a directional reflectivity analysis with an ad-hoc experimental facility was carried out in order to measure the angular distribution of reflected energy by the tested samples.

\subsubsection{Spectrophotometric Analysis}

Reflectance of the samples in the solar spectrum was investigated by a Shimadzu SolidSpec 3700 spectrophotometer equipped with a $60 \mathrm{~mm}$ integrating sphere. Characteristics of the spectrophotometer facility can be found in [24]. The aim of these measurements was to assess the global hemispherical solar reflectance and its spectral distribution. In Figure 2 below, an example of the test carried out through the spectrophotometric analysis with the $R_{\text {SW }}$ sample is shown.

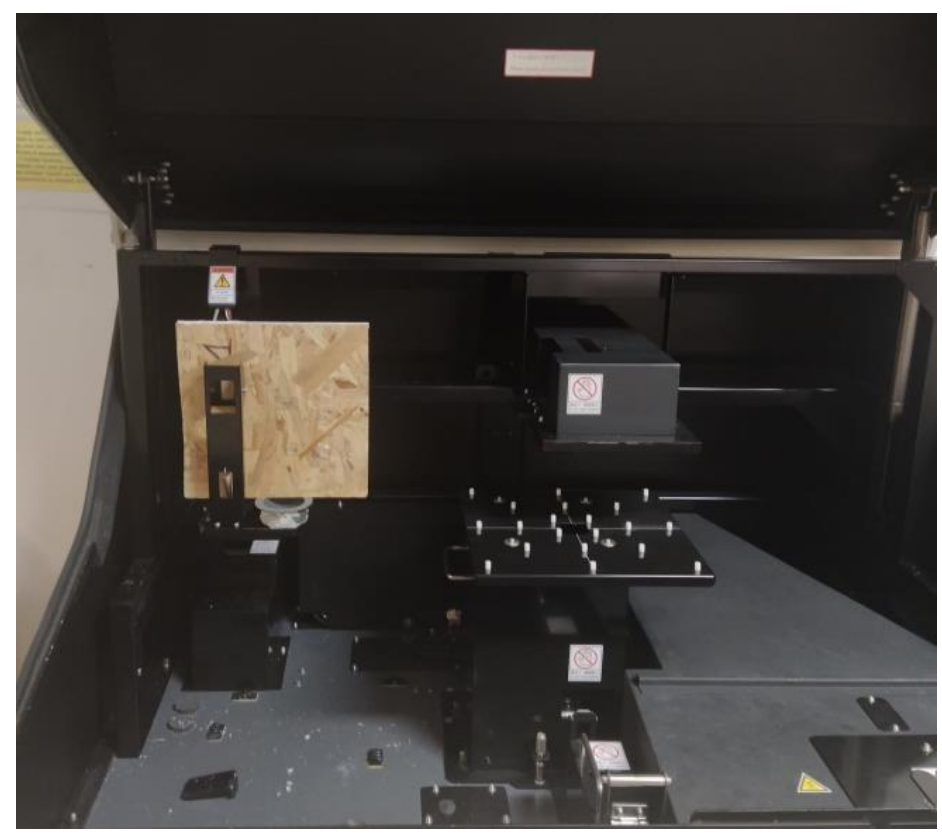

Figure 2. Spectrophotometric analysis of the tested samples.

\subsubsection{Angular Reflectivity Analysis}

As stated in Rossi et al. [14], the most common in-field and in-lab testing procedures could not completely describe RR materials' directional reflectivity properties. Thus, an 
ad-hoc experimental facility, already introduced in [25], has been used for the investigation of RR materials' angular reflectivity for different directions of incident radiation. As shown in Figure 3a, the apparatus is mainly composed of: (i) an artificial light source which illuminates the samples [26]; (ii) a semi-circular frame with a graduated scale from $10^{\circ}$ to $-10^{\circ}$ with respect to the center; (iii) a photo-radiometer Delta Ohm HD 9221 with an LP 9221/RAD probe [27]. In Figure $3 \mathrm{~b}$ below, a picture of the operative conditions for the directivity analysis is presented, where the incident radiation is the one provided only by the artificial light source.

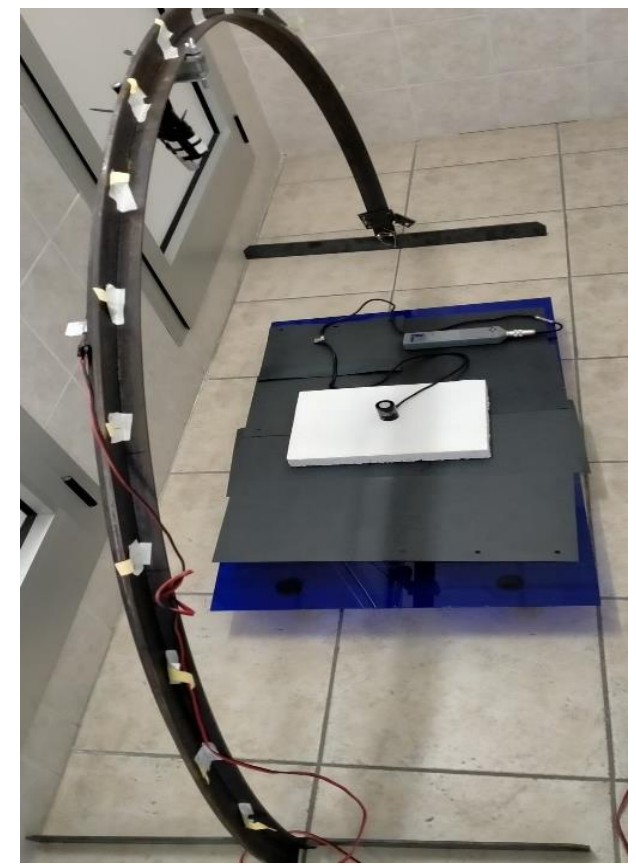

(a)

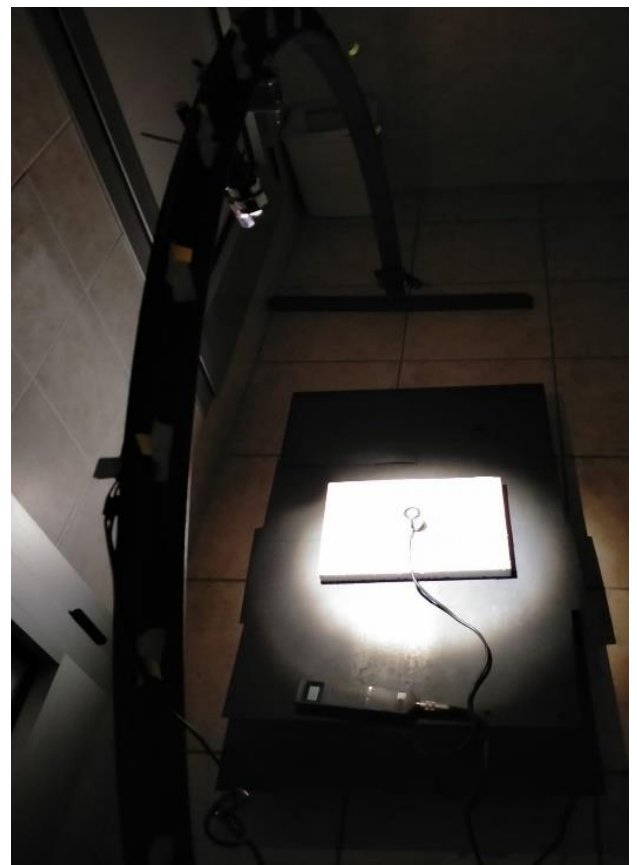

(b)

Figure 3. (a) Experimental facility for directivity analysis; (b) Operative conditions for directivity investigation of samples.

\section{Measurement Results and Discussion}

In this paragraph, results of the optic characterization campaign are discussed.

\subsection{Spectrophotometric Analysis}

Solar reflectance of the samples was determined by spectrophotometric analysis. For each sample, spectrophotometric measurements were carried out three times. Figure 4 shows the average reflectance of samples over the wavelength range. In all cases, it emerges that RR samples show an overall lower reflectance. Over $1500 \mathrm{~nm}$, the reflectance of RR and $R_{R W}$ samples, and their respectively $D_{I F F}$ and $D I F F_{R W}$ ones are very close to each other. The reflectance of $R_{S A}$ and $D_{\text {IFF }}$ samples becomes very close to each other over $1650 \mathrm{~nm}$. From 2000 to $2250 \mathrm{~nm}$, the reflectance of the RR $\mathrm{SW}_{\mathrm{SW}}$ sample corresponds almost exactly to the $D_{I F F}$ sample' s reflectance. Over $2100 \mathrm{~nm}$, the reflectance of the RR sample goes beyond its corresponding diffusive sample. Finally, the reflectance of the

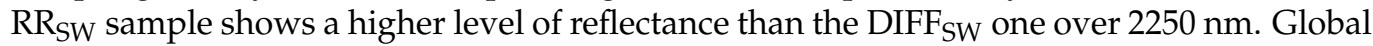
reflectance values are shown in Table 2. 


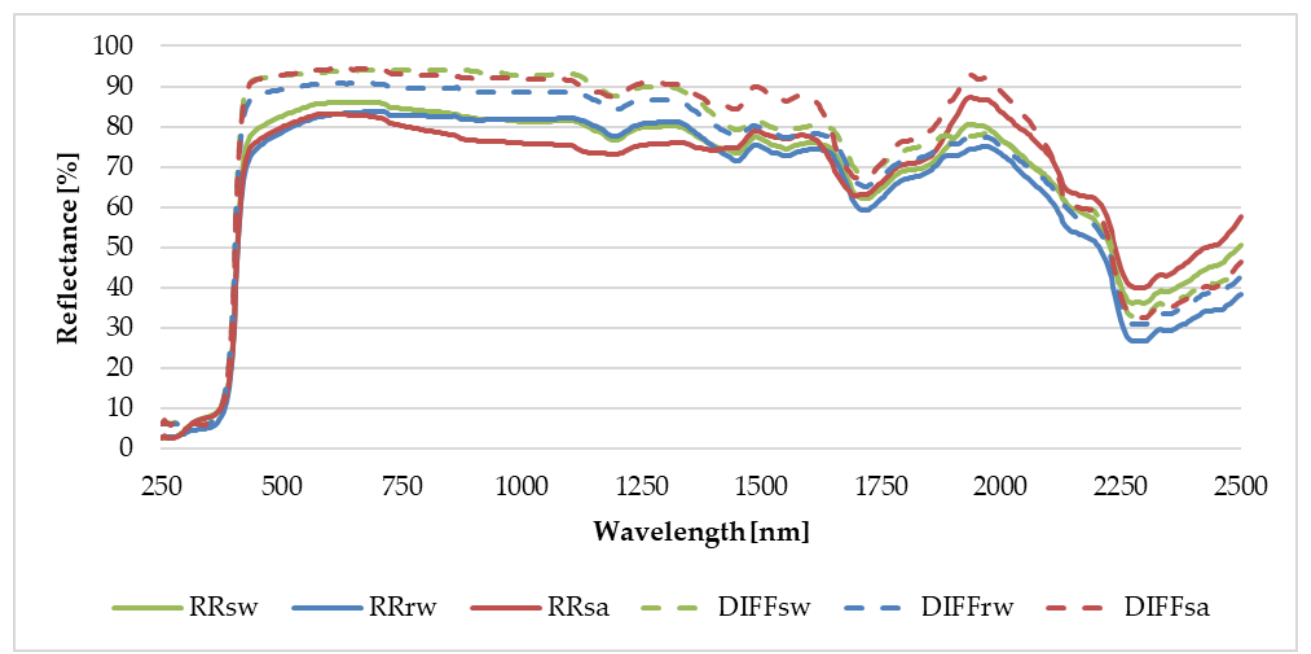

Figure 4. Spectral reflectance of samples.

Table 2. Global reflectance of samples.

\begin{tabular}{cc}
\hline Sample & Global Reflectance (\%) \\
\hline RR $_{S W}$ & 75 \\
RR $_{\text {RW }}$ & 73 \\
RR $_{S A}$ & 72 \\
DIFF $_{S W}$ & 83 \\
DIFF $_{\text {RW }}$ & 80 \\
DIFF $_{\text {SA }}$ & 84 \\
\hline
\end{tabular}

In all cases, diffusive samples show higher global reflectance values than their respective RR samples. The highest value is obtained for the DIFFSA sample, equal to $84 \%$. The RR sample's global reflectance shows the lowest values ranging from $72 \%$ to $75 \%$. Among the RR samples, the $R_{\text {SW }}$ sample shows the highest value, equal to $75 \%$.

Therefore, the diffusive samples, covered by only high-reflective white paint, show a higher global reflectance than that of paints with glass beads layer. In particular, the $\mathrm{RR}_{\mathrm{SA}}$ sample has the lowest global value (72\%) among the three RR samples. Consequently, a smooth substrate made of pine wood or acetate sheet, is able to improve the global reflectance in diffusive samples (i.e., $\mathrm{DIFF}_{\mathrm{SW}}$ and $\mathrm{DIFF}_{\mathrm{SA}}$ ), while the global reflectance of diffusive samples made by a rough plywood substrate (i.e., DIFF $_{\mathrm{RW}}$ ) is negatively affected. Considering the RR samples, the smooth pine wood substrate (i.e., $R_{\text {SW }}$ ) affects positively the global reflectance, while the $R_{S A}$ sample shows a lower global reflectance value compared to the $\mathrm{RR}_{\mathrm{RW}}$ sample.

\subsection{Angular Reflectivity Analysis}

Results of angular reflectivity measurements are reported in Figures 5 and 6. Each graph shows the comparison between the angular reflectivity distribution of different samples, for each direction of the incident radiation. The black arrow indicates the direction from which the incident light strikes the tested sample and the values represent the percentage ratio between the reflected radiation in each direction and the total reflected radiation of the specific sample. 


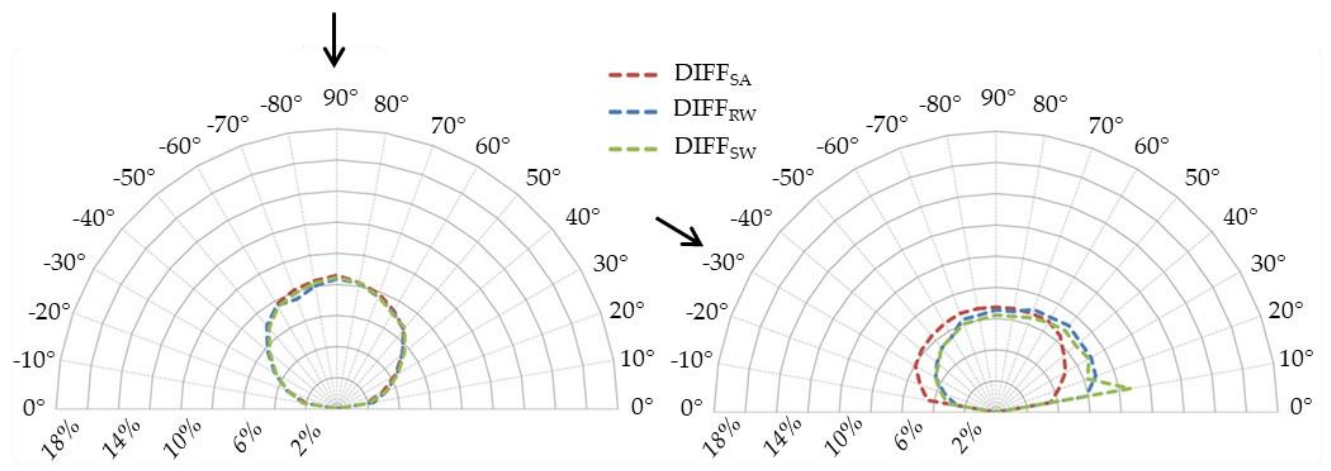

Figure 5. Angular reflectivity profiles of diffusive samples: DIFF $_{\mathrm{SA}}$ (red dotted line), $\mathrm{DIFF}_{\mathrm{RW}}$ (blue dotted line), and $\mathrm{DIFF}_{\mathrm{SW}}$ (green dotted line), for a $90^{\circ}$ and $-30^{\circ}$ angle of incident radiation.

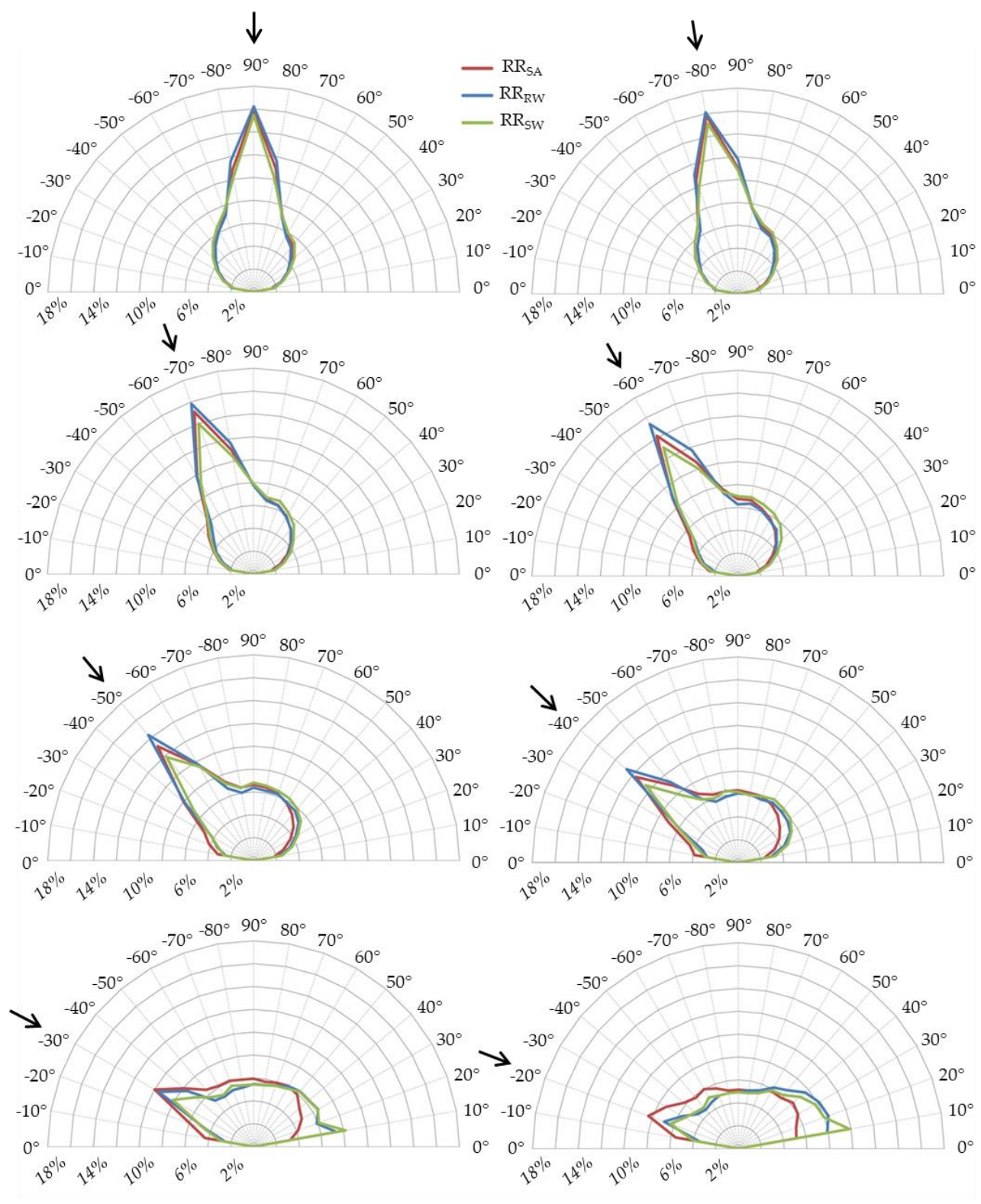

Figure 6. Angular reflectivity profiles of RR samples: $R_{\mathrm{SA}}$ (red solid line), $\mathrm{R}_{\mathrm{RW}}$ (blue solid line), and $\mathrm{RR}_{\mathrm{SW}}$ (green solid line), for each direction of incident radiation from $90^{\circ}$ to $-20^{\circ}$. 
In Figure 5, the comparison between the three diffusive samples is reported, for instance, for an angle of incidence of $90^{\circ}$ and $-30^{\circ}$, respectively. For an incident beam direction normal to the sample, a typical reflectivity distribution following Lambert's law is shown for all the diffusive samples. For an angle of incidence of $-30^{\circ}, \mathrm{DIFF}_{\mathrm{SA}}$ reveals a more symmetrical diffusive distribution, whereas the two wood-based diffusive samples, i.e., $\mathrm{DIFF}_{\mathrm{RW}}$ and $\mathrm{DIFF}_{\mathrm{SW}}$, show a slight rightward shift of their reflectivity profiles, which means that a specular reflection occurs for low incident angles.

Concerning the angular reflectivity of the three RR samples, in Figure 6, the distribution of reflected radiation is represented for each RR sample and for each angle of incidence between $90^{\circ}$ and $-20^{\circ}$, every $10^{\circ}$ steps. Graphs show that a strong retro-reflective component was found for all the RR samples, due to the effect of the glass beads coating. However, small differences in terms of reflectivity distribution among the three RR samples have been detected, depending on the substrate material. Additionally, a diffusive tendency is visible in all RR samples regardless of the angle of incidence of radiation, whereas a specular reflection occurs for low angles of incidence, i.e., from $-40^{\circ}$ to $-20^{\circ}$. Such a specular reflection component is smaller for the $R_{S_{A}}$ sample with respect to the two wood based ones (i.e., $R R_{R W}$ and $R R_{S W}$ ), showing that the smooth acetate substrate performs slightly better in terms of retro-reflection for low angles of incidence.

Values of the percentage ratio between the reflected radiation in the same direction of incidence and the total reflected radiation are reported in Table 3 for the three RR samples. It is clearly evidenced that the $\mathrm{RR}_{\mathrm{RW}}$ sample presents the higher percentage of retro-reflection for high incident angles (i.e., from $90^{\circ}$ to $-40^{\circ}$ ), whereas the $R_{\mathrm{SA}}$ sample performs slightly higher values for $-30^{\circ}$ and $-20^{\circ}$ angles of incidence, with respect to the $\mathrm{RR}_{\mathrm{RW}}$ sample.

Table 3. Retro-reflectivity of the three RR samples, for each angle of incident radiation. Percentage values are referred to the ratio between the radiation reflected back to the source and the total reflected radiation for each sample. The RR sample with the maximum retro-reflective percentage is highlighted in bold for each angle of incidence.

\begin{tabular}{cccc}
\hline Angle of Incidence & $\mathbf{R R}_{\mathbf{S A}}$ & $\mathbf{R R}_{\mathbf{R W}}$ & $\mathbf{R R}_{\mathbf{S W}}$ \\
\hline $90^{\circ}$ & $15.86 \%$ & $\mathbf{1 6 . 2 2} \%$ & $15.47 \%$ \\
$-80^{\circ}$ & $15.83 \%$ & $\mathbf{1 6 . 1 2} \%$ & $15.12 \%$ \\
$-70^{\circ}$ & $15.10 \%$ & $\mathbf{1 5 . 8 4} \%$ & $13.99 \%$ \\
$-60^{\circ}$ & $14.16 \%$ & $\mathbf{1 5 . 3 5 \%}$ & $12.98 \%$ \\
$-50^{\circ}$ & $13.04 \%$ & $\mathbf{1 4 . 3 4 \%}$ & $11.83 \%$ \\
$-40^{\circ}$ & $11.66 \%$ & $\mathbf{1 2 . 7 2} \%$ & $10.53 \%$ \\
$-30^{\circ}$ & $\mathbf{9 . 9 9 \%}$ & $9.57 \%$ & $8.16 \%$ \\
$-20^{\circ}$ & $\mathbf{8 . 3 7 \%}$ & $6.90 \%$ & $6.34 \%$ \\
\hline
\end{tabular}

\section{Conclusions and Future Developments}

The present work aims at investigating the potential effect of a different substrate material on the optic performance of a RR coating, made of a high-reflective white paint with glass beads embedded on it. To this aim, three different substrate materials, characterized also by a different roughness, have been selected: a smooth pine wood panel (SW), a rough plywood panel (RW), and a smooth acetate sheet (SA). With these substrate materials, three $R R$ samples (i.e., $R_{S W}, R_{R W}, R_{S A}$ ) and three diffusive (i.e., $D_{F F} F_{S W}, D_{F F} F_{R W}, D_{F F}$ ) coatings have been realized over the aforementioned samples. The optic performance of each sample has been investigated through a spectrophotometer and an angular reflectivity analysis, using an ad-hoc experimental facility. The main findings are presented in the following points:

- Concerning spectrophotometric analysis, RR samples exhibit lower global reflectance values with respect to the corresponding diffusive samples. $\mathrm{DIFF}_{\mathrm{SA}}$ and $\mathrm{RR}_{\mathrm{SW}}$ samples performed the highest values of global reflectance, equal to $84 \%$ and $75 \%$, respectively; 
- From 300 to $1500 \mathrm{~nm}$, the diffusive samples show always a higher spectral reflectance, whereas both the $\mathrm{RR}_{\mathrm{SA}}$ and the $\mathrm{RR}_{\mathrm{SW}}$ samples becomes higher than the corresponding diffusive samples, from 2110 and $2250 \mathrm{~nm}$, respectively;

- Concerning the angular reflectivity analysis, $R_{R W}$, which is the roughest material, also exhibits the highest retro-reflective component for incident angles near the normal (i.e., from $90^{\circ}$ to $-40^{\circ}$ ). For lower angles of incidence (i.e., $-30^{\circ}$ and $-20^{\circ}$ ), $R R_{S A}$ exhibits a better retro-reflective performance, whereas the two wood-based samples (i.e., $R_{S W}$ and $R R_{R W}$ ) reveal a specular reflection tendency, which becomes predominant for the $-20^{\circ}$ incidence angle;

- The maximum retro-reflective capability is equal to $16.22 \%$ for sample $R R_{R W}$ at a $90^{\circ}$ angle of incident radiation.

Future research efforts should be made in the investigation of materials characterized by different roughness and glass beads properties, in order to identify the optimal RR coating design for building applications, especially in urban canyons. Furthermore, RR materials could be useful in photovoltaic systems, in combination with diffusive materials in order to increase the electric energy produced by the downward photovoltaic panel.

Author Contributions: Conceptualization, A.D.G., M.C. and F.R.; methodology, B.C.; validation, M.F. and A.N.; formal analysis, A.D.G. and M.C.; investigation, A.D.G., M.C., B.C. and L.P.; data curation, A.M.G.; writing—original draft preparation, A.D.G. and M.C.; writing—review and editing, B.C., A.N.; supervision, F.R.; project administration, B.C., A.N. and F.R.; funding acquisition, F.R. All authors have read and agreed to the published version of the manuscript.

Funding: The present experimental research was funded by the Italian Ministry of University and Scientific Research (MIUR) under the PON Project entitled "BEST4U_Bifacial Efficient Solar Cell Technology with 4-Terminal Architecture for Utility Scale".

Institutional Review Board Statement: Not applicable.

Informed Consent Statement: Not applicable.

Data Availability Statement: Not applicable.

Acknowledgments: The authors would like to acknowledge the MIUR and CIRIAF, University of Perugia for financially supporting the activities. Authors would like to thank also INDEX Construction Systems and Products S.p.A. and PROCHIMA s.r.l., for providing the white paint and the glass beads for the experimental investigation, respectively.

Conflicts of Interest: The authors declare no conflict of interest.

\section{References}

1. Santamouris, M. Analyzing the heat island magnitude and characteristics in one hundred Asian and Australian cities and regions. Sci. Total Environ. 2015, 512-513, 582-598. [CrossRef] [PubMed]

2. Deilami, K.; Kamruzzaman, M.; Liu, Y. Urban heat island effect: A systematic review of spatio-temporal factors, data, methods, and mitigation measures. Int. J. Appl. Earth Obs. Geoinf. 2018, 67, 30-42. [CrossRef]

3. Oke, T.R. The Heat Island of the Urban Boundary Layer: Characteristics, Causes and Effects. In Wind Climate in Cities, 1st ed.; Cermak, J.E., Davenport, A.G., Plate, E.J., Viegas, D.X., Eds.; NATO ASI Series (Series E: Applied Sciences); Springer: Dordrecht, The Netherlands, 1995; Volume 277, pp. 81-107. [CrossRef]

4. Khan, H.S.; Paolini, R.; Santamouris, M.; Caccetta, P. Exploring the Synergies between Urban Overheating and Heatwaves (HWs) in Western Sydney. Energies 2020, 13, 470. [CrossRef]

5. Santamouris, M. Recent progress on urban overheating and heat island research. Integrated assessment of the energy, environmental, vulnerability and health impact. Synergies with the global climate change. Energy Build. 2020, 207, 109482. [CrossRef]

6. Zinzi, M.; Agnoli, S.; Burattini, C.; Mattoni, B. On the thermal response of buildings under the synergic effect of heat waves and urban heat island. Sol. Energy 2020, 211, 1270-1282. [CrossRef]

7. Yenneti, K.; Ding, L.; Prasad, D.; Ulpiani, G.; Paolini, R.; Haddad, S.; Santamouris, M. Urban Overheating and Cooling Potential in Australia: An Evidence-Based Review. Climate 2020, 8, 126. [CrossRef]

8. Mohajerani, A.; Bakaric, J.; Jeffrey-Bailey, T. The urban heat island effect, its causes, and mitigation, with reference to the thermal properties of asphalt concrete. J. Environ. 2017, 197, 522-538. [CrossRef] [PubMed] 
9. Santamouris, M.; Young Yun, G. Recent development and research priorities on cool and super cool materials to mitigate urban heat island. Renew. Energy 2020, 161, 792-807. [CrossRef]

10. Xie, N.; Li, H.; Abdelhady, A.; Harvey, J. Laboratorial investigation on optical and thermal properties of cool pavement nanocoatings for urban heat island mitigation. Build. Environ. 2019, 147, 231-240. [CrossRef]

11. Santamouris, M.; Synnefa, A.; Karlessi, T. Using advanced cool materials in the urban built environment to mitigate heat islands and improve thermal comfort conditions. Sol. Energy 2011, 85, 3085-3102. [CrossRef]

12. Yuan, J.; Emura, K.; Farnham, C. A study on the durability of a glass bead retro-reflective material applied to building facades. Prog. Org. Coat. 2018, 120, 36-48. [CrossRef]

13. Yuan, J.; Emura, K.; Farnham, C. A method to measure retro-reflectance and durability of retro-reflective materials for building outer walls. J. Build. Phys. 2015, 38, 500-516. [CrossRef]

14. Rossi, F.; Pisello, A.L.; Nicolini, A.; Filipponi, M.; Palombo, M. Analysis of retro-reflective surfaces for urban heat island mitigation: A new analytical model. Appl. Energy 2014, 114, 621-631. [CrossRef]

15. Yuan, J.; Farnham, C.; Emura, K. Development of a retro-reflective material as building coating and evaluation on albedo of urban canyons and building heat loads. Energy Build. 2015, 103, 107-117. [CrossRef]

16. Rossi, F.; Castellani, B.; Presciutti, A.; Morini, E.; Anderini, E.; Filipponi, M.; Nicolini, A. Experimental evaluation of urban heat island mitigation potential of retro-reflective pavement in urban canyons. Energy Build. 2016, 126, 340-352. [CrossRef]

17. Rossi, F.; Morini, E.; Castellani, B.; Nicolini, A.; Bonamente, E.; Anderini, E.; Cotana, F. Beneficial effects of retroreflective materials in urban canyons: Results from seasonal monitoring campaign. J. Phys. Conf. Ser. 2015, 655, 012012. [CrossRef]

18. Yuan, J.; Emura, K.; Farnham, C. Geometrical-optics analysis of reflective glass beads applied to building coatings. Sol. Energy 2015, 122, 997-1010. [CrossRef]

19. Yuan, J.; Emura, K.; Sakai, H.; Farnham, C.; Lu, S. Optical analysis of glass bead retro-reflective materials for urban heat island mitigation. Sol. Energy 2016, 132, 203-213. [CrossRef]

20. Sakai, H.; Iyota, H. Development of Two New Types of Retroreflective Materials as Countermeasures to Urban Heat Island. Int. J. Thermophys. 2017, 38, 131. [CrossRef]

21. Guo, J.; Guo, Y.; Pan, J. A retroreflective BRDF model based on prismatic sheeting and microfacet theory. Graph. Models 2018, 96, 38-46. [CrossRef]

22. Castellani, B. Application of retro-reflective materials in urban canyon at different geographical locations. Build. Environ. 2021, 193, 107676. [CrossRef]

23. Taylor Hobson Precision Surtronic 25 Datasheet. Available online: http://tecnoquality.eu/wp-content/uploads/2017/02/ surtronic25it.pdf (accessed on 13 May 2021).

24. Website of Spectrophotometer C101-E167 SolidSpec-3700i/3700i DUV Datasheet. Available online: Shimadzu.com (accessed on 31 March 2021).

25. Gambelli, A.M.; Cardinali, M.; Filipponi, M.; Castellani, B.; Nicolini, A.; Rossi, F. A normalization procedure to compare retroreflective and traditional diffusive materials in terms of UHI mitigation potential. Proc. AIP Conf. Proc. 2019, $2191,020085$. [CrossRef]

26. Website of Zoom IP Rated Projectors Datasheet. Available online: https://cdn.flexalighting.net/media/Download/ZOOM-ST. pdf (accessed on 31 March 2021).

27. Website of Products-Delta OHM Datasheet. Available online: https://www.deltaohm.com/it/prodotti/ (accessed on 31 March 2021). 